Ophthalmologe 2022 1119 (Suppl 2):S149 https://doi.org/10.1007/s00347-021-01517-y Online publiziert: 8. Oktober 2021

() Der/die Autor(en) 2021

\section{Erratum zu: Unilaterale Netzhautblutungen bei Säuglingen - 2 Fälle von Schütteltrauma?}

\author{
T. Barth ${ }^{1}$ (D) - M. Altmann' · C. Batzlsperger ${ }^{2} \cdot$ H. Jägle $\cdot$ H. Helbig' \\ ${ }^{1}$ Klinik und Poliklinik für Augenheilkunde, Universitätsklinikum Regensburg, Regensburg, Deutschland \\ ${ }^{2}$ Klinik für Kinder- und Jugendmedizin, Neonatologie, Neuropädiatrie, DONAUISAR Klinikum Deggendorf, \\ Deggendorf, Deutschland
}

Die Online-Version des Originalartikels ist unter https://doi.org/10.1007/s00347-020-01038-0 zu finden.

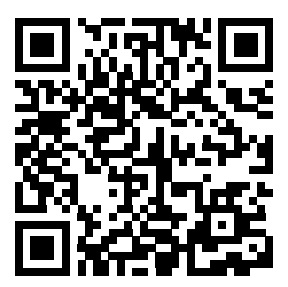

QR-Code scannen \& Beitrag online lesen

\section{Erratum zu:}

Ophthalmologe 2020

https://doi.org/10.1007/s00347-020-

01038-0

Der Artikel „Unilaterale Netzhautblutungen bei Säuglingen - 2 Fälle von Schütteltrauma?" von T. Barth, M. Altmann, C. Batzlsperger, $H$. Jägle und $H$. Helbig wurde ursprünglich Online First ohne „Open Access" auf der Internetplattform des Verlags publiziert. Nach der Veröffentlichung in Band 117 Heft 10 pp. 1033-1036 hatten sich die Autoren für eine „Open Access"-Veröffentlichung entschieden. Das Urheberrecht des Artikels wurde deshalb in (c) Der/die Autor(en) 2020 geändert. Dieser Artikel ist jetzt unter der Creative Commons Namensnennung 4.0 International Lizenz veröffentlicht, welche die Nutzung, Vervielfältigung, Bearbeitung, Verbreitung und Wiedergabe in jeglichem Medium und Format erlaubt, sofern Sie den/die ursprünglichen Autor(en) und die Quelle ordnungsgemäß nennen, einen Link zur Creative Commons Lizenz beifügen und angeben, ob Änderungen vorgenommen wurden.

Die in diesem Artikel enthaltenen Bilder und sonstiges Drittmaterial unterliegen ebenfalls der genannten Creative Commons Lizenz, sofern sich aus der Abbildungslegende nichts anderes ergibt. Sofern das betreffende Material nicht unter der genannten Creative Commons Lizenz steht und die betreffende Handlung nicht nach gesetzlichen Vorschriften erlaubt ist, ist für die oben aufgeführten
Weiterverwendungen des Materials die Einwilligung des jeweiligen Rechteinhabers einzuholen.

Weitere Details zur Lizenz entnehmen Sie bitte der Lizenzinformation auf http://creativecommons.org/licenses/by/ 4.0/deed.de.

Der Originalbeitrag wurde korrigiert.

\section{Korrespondenzadresse}

\section{Dr. med. T. Barth, FEBO, MHBA}

Klinik und Poliklinik für Augenheilkunde, Universitätsklinikum Regensburg Franz-Josef-Strauß-Allee 11, 93053 Regensburg, Deutschland teresa.barth@ukr.de

Open Access. Dieser Artikel wird unter der Creative Commons Namensnennung 4.0 International Lizenz veröffentlicht, welche die Nutzung, Vervielfältigung, Bearbeitung, Verbreitung und Wiedergabe in jeglichem Medium und Format erlaubt, sofern Sie den/die ursprünglichen Autor(en) und die Quelle ordnungsgemäß nennen, einen Link zur Creative Commons Lizenz beifügen und angeben, ob Änderungen vorgenommen wurden.

Die in diesem Artikel enthaltenen Bilder und sonstiges Drittmaterial unterliegen ebenfalls der genannten Creative Commons Lizenz, sofern sich aus der Abbildungslegende nichts anderes ergibt. Sofern das betreffende Material nicht unter der genannten Creative Commons Lizenz steht und die betreffende Handlung nicht nach gesetzlichen Vorschriften erlaubt ist, ist für die oben aufgeführten Weiterverwendungen des Materials die Einwilligung des jeweiligen Rechteinhabers einzuholen.

Weitere Details zur Lizenz entnehmen Sie bitte der Lizenzinformation auf http://creativecommons.org/ licenses/by/4.0/deed.de. 